Relations industrielles

Industrial Relations

\title{
Hommage à Lise Poulin Simon, 1937-1995
}

\section{Esther Déom}

Volume 51, numéro 1, 1996

URI : https://id.erudit.org/iderudit/051071ar

DOI : https://doi.org/10.7202/051071ar

Aller au sommaire du numéro

\section{Éditeur(s)}

Département des relations industrielles de l'Université Laval

\section{ISSN}

0034-379X (imprimé)

1703-8138 (numérique)

Découvrir la revue

\section{Citer ce document}

Déom, E. (1996). Hommage à Lise Poulin Simon, 1937-1995. Relations

industrielles / Industrial Relations, 51(1), 3-3. https://doi.org/10.7202/051071ar

Tous droits réservés @ Département des relations industrielles de l'Université Laval, 1996
Ce document est protégé par la loi sur le droit d'auteur. L’utilisation des services d'Érudit (y compris la reproduction) est assujettie à sa politique d'utilisation que vous pouvez consulter en ligne.

https://apropos.erudit.org/fr/usagers/politique-dutilisation/ 


\section{Hommage à Lise Poulin Simon, 1937-1995}

Lise Poulin Simon était professeure au Département des relations industrielles depuis 1987. Pendant ces quelques années, trop peu nombreuses, passées au Département, Lise s'est imposée, à sa manière, soit avec une assurance tranquille et un profond respect pour les autres, comme une collègue et pour plusieurs, une amie, hors de l'ordinaire.

Lise a toujours foumi des enseignements de très haute qualité et sa disponibilité et son intérêt pour les étudiantes et étudiants, pour ses collègues professeurs et professeures étaient bien reconnus. En plus d'être une enseignante très appréciée, Lise possédait toutes les qualités et les compétences d'une chercheure. Les nombreuses recherches qu'elle a conduites, seule ou en collaboration avec d'autres chercheures et chercheurs, ainsi que ses nombreuses publications dans différents réseaux, ses conférences, ses participations aux travaux de divers comités lui conféraient une reconnaissance qui dépassait largement le cadre du Département. Son important ouvrage Le défi du plein emploi : un nouveau regard économique (en collaboration avec Diane Bellemarre) lui a valu une très grande reconnaissance au Québec, au Canada et à l'étranger, où elle était souvent invitée pour prononcer des conférences. Lise était préoccupée par le développement et surtout la transmission des connaissances et ses publications, de nature diverse, ont su atteindre avec autant d'impact le milieu scientifique que celui des praticiennes et praticiens en relations industrielles.

Lise a agi à titre de conseillère, consultante, experte-conseil pour différents organismes comme la Société québécoise de développement de la main-d'œuvre, le Comité exécutif de la Ville de Montréal, la Commission des droits de la personne, l'Assemblée des Évêques du Québec et bien d'autres. Il convient de souligner plus particulièrement les lourdes responsabilités qu'elle a assumées dans la création et l'organisation du Forum pour l'emploi. Lise a également occupé le poste de Secrétaire adjointe au Secrétariat à l'Emploi et à la Concertation (19851986) et sa compétence avait été récemment mise encore plus en lumière quand le gouvernement du Québec lui a demandé d'assumer le poste de Secrétaire adjointe au Secrétariat à la Concertation.

Les séjours à l'étranger de Lise, sa participation à des colloques et congrès internationaux et à des missions de recherche de même que ses contacts avec des chercheures et chercheurs de différentes nationalités en faisaient une personne ouverte aux différentes tendances et différentes cultures.

Le décès de notre collègue, le 11 août 1995, nous a profondément attristés. Le Département des relations industrielles et la société québécoise perdent une grande dame, une personnalité hors du commun. Son absence se fera cruellement sentir dans tous les milieux, patronaux, syndicaux, communautaires et gouvernementaux, intéressés par les questions d'emploi et de travail. Cependant, son courage, sa détermination, son implication sauront sans nul doute animer ceux et celles qui restent et pour qui elle demeurera une source d'inspiration. $\mathrm{Au}$ revoir Lise, tu nous manqueras.

ESTHER DÉOM, directrice 